\title{
Arsenic speciation analysis of urine samples from individuals living in an arsenic-contaminated area in Bangladesh
}

\author{
Akihisa Hata - Kenzo Yamanaka • Mohamed Ahsan Habib • \\ Yoko Endo • Noboru Fujitani • Ginji Endo
}

Received: 7 April 2011/Accepted: 4 October 2011/Published online: 3 November 2011

(C) The Japanese Society for Hygiene 2011

\begin{abstract}
Objectives Chronic inorganic arsenic (iAs) exposure currently affects tens of millions of people worldwide. To accurately determine the proportion of urinary arsenic metabolites in residents continuously exposed to iAs, we performed arsenic speciation analysis of the urine of these individuals and determined whether a correlation exists between the concentration of iAs in drinking water and the urinary arsenic species content.

Methods The subjects were 165 married couples who had lived in the Pabna District in Bangladesh for more than 5 years. Arsenic species were measured using high-performance liquid chromatography and inductively coupled plasma mass spectrometry.

Results The median iAs concentration in drinking water was $55 \mu \mathrm{gAs} / \mathrm{L}$ (range $<0.5-332 \mu \mathrm{gAs} / \mathrm{L}$ ). Speciation
\end{abstract}

A. Hata · M. A. Habib · G. Endo ( $\square)$

Department of Preventive Medicine and Environmental Health, Graduate School of Medicine, Osaka City University,

1-4-3 Asahimachi, Abeno-ku, Osaka 545-8585, Japan

e-mail: endog@med.osaka-cu.ac.jp

A. Hata $\cdot$ N. Fujitani

Department of Medical Risk and Crisis Management,

Faculty of Risk and Crisis Management,

Chiba Institute of Science, Chiba, Japan

K. Yamanaka

Research Unit of Environmental Toxicology

and Carcinogenesis, College of Pharmacy,

Nihon University, Chiba, Japan

Y. Endo

Research Center for Occupational Poisoning, Kansai Rosai Hospital, Japan Labour Health and Welfare Organization, Hyogo, Japan analysis revealed the presence of arsenite, arsenate, monomethylarsonic acid (MMA), and dimethylarsinic acid in urine samples with medians (range) of 16.8 (7.7-32.3), 1.8 $(<0.5-3.3), \quad 13.7$ (5.6-25.0), and 88.6 $\mu \mathrm{gAs} / \mathrm{L}$ (47.9$153.4 \mu \mathrm{gAs} / \mathrm{L})$, respectively. No arsenobetaine or arsenocholine was detected. The concentrations of the 4 urinary arsenic species were significantly and linearly related to each other. The urinary concentrations of total arsenic and each species were significantly correlated with the iAs concentration of drinking water.

Conclusions All urinary arsenic species are well correlated with each other and with iAs in drinking water. The most significant linear relationship existed between the iAs concentration in drinking water and urinary iAs + MMA concentration. From these results, combined with the effects of seafood ingestion, the best biomarker of iAs exposure is urinary iAs + MMA concentration.

Keywords Arsenic - HPLC-ICP-MS - Speciation analysis · Urine $\cdot$ Drinking water

\section{Introduction}

In Bangladesh, the United Nations International Children's Emergency Fund (UNICEF) and other nongovernmental organizations encouraged a massive shift from drinking microbially contaminated surface water to groundwater accessed by tube wells to reduce infant mortality associated with diarrheal diseases in the 1960s. In the 1990s, it was discovered that roughly one-half of these wells contained high concentrations of arsenic [1, 2]. Since then, many epidemiological studies have been conducted. We previously reported the relationship between inorganic arsenic (iAs) concentrations in well water and the total urinary 
arsenic concentrations of residents living in the Pabna District of Bangladesh - an area in which groundwater is contaminated by arsenic - to examine the effectiveness of the arsenic mitigation program [3]. We found that greenmarked wells, which the Bangladesh government regards as safe, are not always safe.

The International Agency for Research on Cancer (IARC) concludes that there is sufficient epidemiological evidence for the toxicity of iAs in humans such as carcinogenicity of the lungs, skin, and urinary bladder [4]. Methylation of iAs to monomethylarsonic acid (MMA) and dimethylarsinic acid (DMA) has been demonstrated in humans and several mammalian species [5]. These metabolites are less reactive in tissue constituents than iAs and are readily excreted in urine. However, reactive intermediates of trivalent MMA and DMA (MMA ${ }^{\mathrm{III}}$ and $\mathrm{DMA}^{\mathrm{III}}$ ) produced in iAs metabolic processing in mammals may be responsible for the observed carcinogenic effects [6-9]. Therefore, in 2010, the IARC classified MMA and DMA as group 2B compounds, and arsenobetaine (AsBe) and other organic arsenic compounds that are not metabolized in humans as group 3 compounds [10]. Since toxicities of arsenic-based compounds vary greatly due to their different chemical configurations, relative proportions of urinary metabolites of iAs have been identified as potential biomarkers of susceptibility to iAs toxicity [5, 11-13]. Recently, chemical speciation analysis using high-performance liquid chromatography with inductively coupled plasma mass spectrometry (HPLC-ICP-MS) has been used to monitor iAs exposure. Because HPLC-ICPMS analysis can determine whether subjects have ingested seafood and the presence or absence of arsenic metabolites more precisely than hydride generation atomic absorption spectrophotometry (HG-AAS), HPLC-ICP-MS is indispensable for biological monitoring of residents exposed to iAs.

Speciation analysis of urinary arsenic has been conducted among populations who drink arsenic-polluted water [14-16]; however, the relationships between each urinary arsenic species are not reported. To accurately determine the proportions of urinary arsenic metabolites of individuals continuously exposed to iAs, we performed arsenic speciation analysis of the urine of residents drinking iAs-contaminated water who do not ingest organic arsenic from seafood. We used HPLC-ICP-MS to examine the relationships between urinary arsenic speciation levels and iAs concentrations in drinking water.

\section{Materials and methods}

\section{Subjects}

The subjects were residents of 17 villages in the Pabna District in Bangladesh, which is located northwest of the capital city of Dhaka [3]. Inhabitants of these villages are entirely dependent on the water supplies of tube wells that were installed by individual households, the government, or nongovernmental organizations. Subjects were chosen from volunteers gathered through community recruitment in this area. We recruited families that had lived in the area for at least 5 years before recruitment in which the husband had not engaged in seasonal or long-term migratory jobs. Of the families satisfying these entry criteria, approximately one-third of the families in the study area were enrolled. The subjects included 330 residents (165 married couples; 165 males and 165 females) who did not customarily eat seafood. Their profiles are shown in Table 1 . Informed consent was obtained from the subjects. The study protocol was approved by the Ethics Committee of Osaka City University Graduate School of Medicine. After the field procedure was discussed, the Civil Surgeon's office of Pabna District gave permission for research activity in this area. Drinking water concentration is expressed according to the well water concentration for each subject used. When a subject drank water from 2 different wells, the average concentration was used. Water and urine samples were collected in the mornings between May and July 2005 and kept frozen at $-20^{\circ} \mathrm{C}$ at a laboratory in Bangladesh and at $-80^{\circ} \mathrm{C}$ at a laboratory in Japan.

\section{Chemicals}

Sodium arsenite (AsIII), sodium arsenate (AsV), MMA, and $\mathrm{AsBe}$ were purchased from Wako Pure Chemical Industries (Osaka, Japan). DMA, trimethylarsine oxide (TMAO), and arsenocholine (AsCho) were obtained from Tri Chemical Laboratory (Yamanashi, Japan). Germanium standard solution (Kanto Chemical, Tokyo, Japan) was used as an internal standard. $\mathrm{HNO}_{3}$ (Tama Chemicals, Tokyo, Japan), $\mathrm{NH}_{4} \mathrm{NO}_{3}$ (Wako Pure Chemical, Osaka, Japan), and 2,6-pyridinedicarboxylic acid (Tokyo Kasei Industry, Tokyo, Japan) were used for the HPLC mobile phase. Ultrapure water for analysis was prepared using a Milli-Q Element A-10 with a Quantum ICP cartridge (Millipore Japan, Tokyo, Japan).

Analytical conditions

Untreated water samples were obtained and analyzed using ICP-MS as described in our previous report [3].

Total arsenic in urine samples was quantified using an Elan DRCII ICP-MS (PerkinElmer SCIEX, Concord, ON, Canada) under the following conditions: radiofrequency (RF) power $1300 \mathrm{~W}$, gas flow-plasma $15 \mathrm{~L} / \mathrm{min}$, auxiliary flow $1.2 \mathrm{~L} / \mathrm{min}$, nebulizer flow $1.0 \mathrm{~L} / \mathrm{min}$, with platinum sample and skimmer cones. The dynamic reaction cell 
Table 1 Distribution of age, BMI, iAs in drinking water, urinary tAs, sumAs, and urinary creatinine concentrations among 165 married couples

Median difference between males and females tested by Mann-Whitney $U$ test. $p<0.05$ is statistically significant

${ }^{a}$ Values are total arsenic concentrations directly determined by ICP-MS

b Values are concentrations of sum of arsenic compounds detected in speciation analysis

\begin{tabular}{|c|c|c|c|c|c|c|c|}
\hline & $\begin{array}{l}\text { Age } \\
\text { (years) }\end{array}$ & $\begin{array}{l}\text { BMI } \\
\left(\mathrm{kg} / \mathrm{m}^{2}\right)\end{array}$ & $\begin{array}{l}\text { iAs in drinking } \\
\text { water }(\mu \mathrm{gAs} / \mathrm{L})\end{array}$ & $\begin{array}{l}\text { Urinary } \\
\mathrm{tAs}^{\mathrm{a}} \\
(\mu \mathrm{gAs} / \mathrm{L})\end{array}$ & $\begin{array}{l}\text { Urinary } \\
\text { sumAs }^{\mathrm{b}} \\
(\mu \mathrm{gAs} / \mathrm{L})\end{array}$ & $\begin{array}{l}\text { Urinary } \\
\text { creatinine } \\
(\mathrm{g} / \mathrm{L})\end{array}$ & $\begin{array}{l}\text { Urinary } \\
\text { sumAs } \\
\text { ( } \mu \mathrm{gAs} / \mathrm{g} \\
\text { creatinine) }\end{array}$ \\
\hline \multicolumn{8}{|l|}{ Total (330) } \\
\hline Minimum & 20 & 12.9 & 1 & 3.8 & 2.0 & 0.03 & 28.4 \\
\hline 25 percentile & 30 & 18.7 & 25 & 55.6 & 62.0 & 0.23 & 177.1 \\
\hline Median & 37 & 20.0 & 55 & 118.6 & 126.1 & 0.41 & 323.3 \\
\hline 75 percentile & 46 & 22.2 & 86 & 200.0 & 222.2 & 0.61 & 541.5 \\
\hline Maximum & 77 & 32.0 & 332 & 2166.0 & 2106.5 & 2.46 & 3420.1 \\
\hline \multicolumn{8}{|l|}{ Male (165) } \\
\hline Minimum & 24 & 14.8 & 1 & 13.0 & 14.9 & 0.05 & 28.4 \\
\hline 25 percentile & 35 & 18.6 & 25 & 63.6 & 68.3 & 0.30 & 149.8 \\
\hline Median & 40 & 19.8 & 55 & 124.2 & 129.2 & 0.47 & 278.4 \\
\hline 75 percentile & 50 & 21.7 & 86 & 202.8 & 226.6 & 0.73 & 477.2 \\
\hline Maximum & 77 & 27.9 & 332 & 874.7 & 1024.9 & 2.16 & 2507.3 \\
\hline \multicolumn{8}{|l|}{ Female (165) } \\
\hline Minimum & 20 & 12.9 & 1 & 3.8 & 2.0 & 0.03 & 33.4 \\
\hline 25 percentile & 27 & 18.7 & 25 & 43.3 & 48.6 & 0.18 & 209.1 \\
\hline Median & 33 & 20.4 & 55 & 109.5 & 124.0 & 0.30 & 369.3 \\
\hline 75 percentile & 42 & 22.4 & 86 & 196.8 & 214.6 & 0.52 & 614.9 \\
\hline Maximum & 61 & 32.0 & 332 & 2166.0 & 2106.5 & 2.46 & 3420.1 \\
\hline $\begin{array}{l}\text { Median } \\
\quad \text { difference }(p)\end{array}$ & $<0.001$ & 0.086 & & 0.368 & 0.582 & $<0.001$ & 0.001 \\
\hline
\end{tabular}

(DRC) mode of operation was set with ammonia $\left(\mathrm{NH}_{3}\right)$ as the reaction gas; the rejection parameter $\mathrm{q}(\mathrm{RPq})$ of the DRC and the flow rate of $\mathrm{NH}_{3}$ were optimized and set to 0.5 and $0.3 \mathrm{~mL} / \mathrm{min}$, respectively. For total arsenic analysis, urine samples were diluted 10-fold with an aqueous solution containing $0.5 \% \mathrm{HNO}_{3}$ (TAMA PURE-AA-10; Tama Chemicals Co. Ltd., Tokyo, Japan), 0.5 g/L ethylenediaminetetraacetic acid (EDTA) (Titriplex II; Merck, Darmstadt, Germany), and $0.5 \mathrm{~g} / \mathrm{L}$ Triton X-100 (Acros Organics, Geel, Belgium). Nonspectral matrix effects observed when DRC was used were confirmed by using $\mathrm{NaCl}$ at $m / z=77$ for $\mathrm{ArCl}$ monitoring. The detection limit for arsenic was $0.24 \mu \mathrm{g} / \mathrm{L}$.

Speciation analysis of urinary arsenic was performed using HPLC-ICP-MS as described in our previous report [17]. Although MMA and DMA exist in 2 different valence states (i.e., trivalent and pentavalent), we did not attempt to distinguish valence states in this study. This analytical procedure was validated using certified reference urine for internal quality control (NIES CRM No. 18 Human Urine; National Institute for Environmental Studies, Japan) and by using the external quality assessment program of the German External Quality Assessment Scheme (Institute of Occupational Social and Environmental Medicine of the University of Erlangen, Nuremberg, Germany) as described in our previous reports $[17,18]$.

\section{Sample preparation}

Frozen urine samples were thawed to room temperature and centrifuged at $3000 \mathrm{rpm}$ for $10 \mathrm{~min}$, and the resultant supernatants were used for analysis. The supernatants were diluted 10-fold with ultrapure water and analyzed using HPLC-ICP-MS as described above.

\section{Statistical analysis}

Data collected by questionnaire and urine measurements were analyzed using the SPSS statistical package (PASW SPSS Statistics 18; IBM Japan, Tokyo, Japan). A correlational analysis among urinary concentrations of arsenic species was performed with $\log _{10}$-transformed values. The median difference was tested using the Mann-Whitney $U$ test.

\section{Results}

The distributions of age; body mass index (BMI); urinary total arsenic (tAs) concentration; the sum of concentrations of all arsenic compounds detected in urine by using HPLC-ICP-MS, including unidentified arsenic compounds (sumAs); iAs in drinking water; and urinary creatinine 
concentrations among the 165 couples are shown in Table 1. Age and urinary creatinine concentration in females were significantly lower than those in males. Inversely, urinary sumAs concentration adjusted for creatinine in females was significantly higher than that in males. Urinary creatinine concentrations ranged from 0.03 to $2.46 \mathrm{~g} / \mathrm{L}$; the medians for males and females were 0.47 and $0.30 \mathrm{~g} / \mathrm{L}$, respectively. Creatinine values were significantly lower than those of Western people $[19,20]$. Next, we analyzed urinary arsenic concentrations without adjusting for creatinine. Urinary sumAs concentrations ranged from 2.0 to $2106.5 \mu \mathrm{gAs} / \mathrm{L}$; the distribution was similar for both sexes. There was good linear agreement between tAs and sumAs: $y=1.07 x+4.55$ (where $y=$ sumAs concentration, $x=$ tAs concentration, $r=0.996)$.

In speciation analysis, AsIII, AsV, MMA, and DMA were detected in urine samples, whereas AsBe, TMAO, and AsCho, which are generated as a result of seafood ingestion, were not detected, as shown in Fig. 1. The medians (range) of AsIII, AsV, MMA, and DMA were $16.8 \mu \mathrm{gAs} / \mathrm{L}(7.7-32.3 \mu \mathrm{gAs} / \mathrm{L}), 1.8 \mu \mathrm{g} / \mathrm{L}(0.5-3.3 \mu \mathrm{gAs} /$ $\mathrm{L}), \quad 13.7 \mu \mathrm{g} / \mathrm{L} \quad(5.6-25.0 \mu \mathrm{gAs} / \mathrm{L}), \quad$ and $\quad 88.6 \mu \mathrm{gAs} / \mathrm{L}$ (47.9-153.4 $\mu \mathrm{gAs} / \mathrm{L})$, respectively. The proportion of each species as well as the methylation indices, the primary methylation index (PMI) of MMA/(AsIII + AsV) and the secondary methylation index (SMI) of DMA/MMA, are shown in Table 2. The most excreted arsenic compound
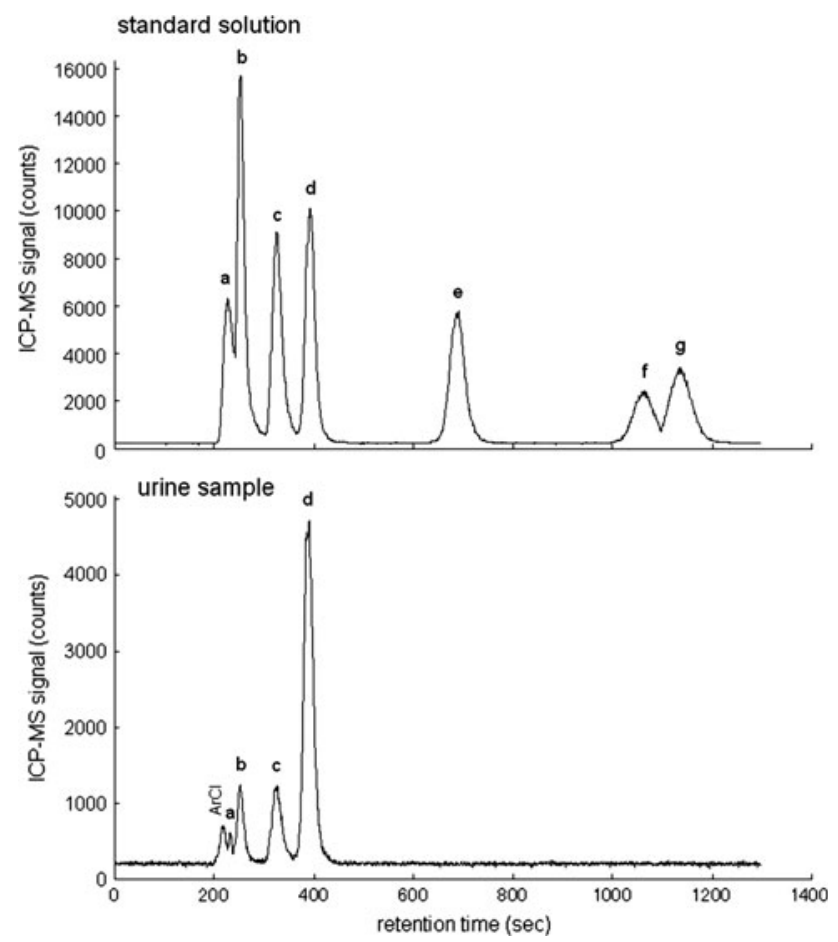

Fig. 1 Chromatograms of a standard solution and urine sample obtained using HPLC-ICP-MS. The peaks show: $a \mathrm{AsV}, b$ MMA, $c$ AsIII, $d$ DMA, $e$ AsBe, $f$ AsCho, and $g$ TMAO was DMA, accounting for approximately $70 \%$ of the total. Significant differences were observed between sexes in the proportions of arsenic species except DMA and iAs + MMA, and methylation indices. The proportion of MMA was significantly higher in males than in females; however, those of AsIII, AsV, and iAs in males were significantly lower than those in females. The SMI value was nearly 10 times greater than that of PMI in both sexes. PMI values in males were significantly higher than those in females, whereas SMI values were significantly lower than those in females.

Urinary arsenic species concentrations were $\log _{10^{-}}$ transformed; the relationship between each species is shown in Fig. 2. All regressions among the 4 species were significantly positive with Pearson's correlation coefficients $(r)$ ranging from 0.6 to 0.9 ; the most strongly correlated relationship was obtained between $\log$ (MMA) and $\log ($ DMA) (Table 3). Moreover, $\log (\mathrm{iAs}+\mathrm{MMA})$ exhibited significant positive linear relationships both with $\log$ (DMA) and $\log$ (sumAs) with $r$ values of 0.92 and 0.96 , respectively (Table 3 ).

The regression analysis between arsenic in drinking water and urinary arsenic species is shown in Fig. 3, and related equations are shown in Table 4. All urinary arsenic species were well correlated with arsenic in drinking water with correlation coefficients from 0.50 to 0.61 . The relationship between urinary iAs + MMA concentration with arsenic in drinking water exhibited the best linearity. Concentrations of iAs + MMA and sumAs against $50 \mu \mathrm{gAs} / \mathrm{L}$ drinking water were estimated to be 35.4 and $132.7 \mu \mathrm{gAs} / \mathrm{L}$, respectively.

The effects of iAs concentration in drinking water, BMI, urinary creatinine concentration, and age on the proportion of arsenic species and methylation indices were examined. Table 5 shows clear differences in arsenic effects with respect to sex. Concentration of iAs in drinking water was positively correlated with PMI but negatively with SMI; statistical significance was observed in males and totals but not in females alone. BMI was negatively correlated with MMA (\%) and PMI, and statistical significance was observed in females and totals but not in males alone. Creatinine exhibited no significant effect for either sex. Age was significantly positively correlated with PMI but not SMI in both sexes.

\section{Discussion}

This study determined the relationships among species of urinary arsenic in residents drinking arsenic-polluted water. Distribution and correlation analyses revealed strong correlations between the $\log _{10}$-transformed concentrations of each arsenic species exceeding 0.8, except regarding the 
Table 2 Proportion of urinary arsenic species and methylation indices among 330 subjects

\begin{tabular}{|c|c|c|c|c|c|c|c|c|}
\hline & \multicolumn{6}{|c|}{ Proportion (\%) } & \multicolumn{2}{|c|}{ Methylation indices } \\
\hline & AsIII & AsV & MMA & DMA & $\mathrm{iAs}^{\mathrm{a}}$ & $\mathrm{iAs}+\mathrm{MMA}$ & PMI & SMI \\
\hline \multicolumn{9}{|l|}{ Total (330) } \\
\hline 25 percentile & 10.4 & 0.9 & 8.2 & 68.0 & 12.0 & 22.1 & 0.51 & 4.95 \\
\hline Median & 13.4 & 1.5 & 10.9 & 73.2 & 15.4 & 26.7 & 0.68 & 6.65 \\
\hline 75 percentile & 16.5 & 2.3 & 13.9 & 77.8 & 18.9 & 31.7 & 1.00 & 9.25 \\
\hline \multicolumn{9}{|l|}{ Male (165) } \\
\hline 25 percentile & 9.9 & 0.7 & 9.2 & 68.3 & 11.3 & 21.9 & 0.63 & 4.56 \\
\hline Median & 12.6 & 1.2 & 12.2 & 73.5 & 13.9 & 26.5 & 0.84 & 6.03 \\
\hline 75 percentile & 15.7 & 1.8 & 15.2 & 78.1 & 17.0 & 31.5 & 1.10 & 8.41 \\
\hline \multicolumn{9}{|l|}{ Female (165) } \\
\hline 25 percentile & 11.1 & 1.2 & 7.6 & 67.7 & 13.0 & 22.2 & 0.46 & 5.53 \\
\hline Median & 14.6 & 1.8 & 10.0 & 73.0 & 16.8 & 26.8 & 0.59 & 7.10 \\
\hline 75 percentile & 17.6 & 2.7 & 12.7 & 77.7 & 19.9 & 32.2 & 0.77 & 10.03 \\
\hline Median difference $(p)$ & 0.001 & $<0.001$ & $<0.001$ & 0.912 & 0.001 & 0.912 & $<0.001$ & 0.011 \\
\hline
\end{tabular}

Median difference between males and females tested by Mann-Whitney $U$ test. $p<0.05$ is statistically significant

$P M I$ primary methylation index calculated from urinary MMA/iAs, SMI secondary methylation index calculated from urinary DMA/MMA

${ }^{a}$ Values are sum of AsIII and AsV
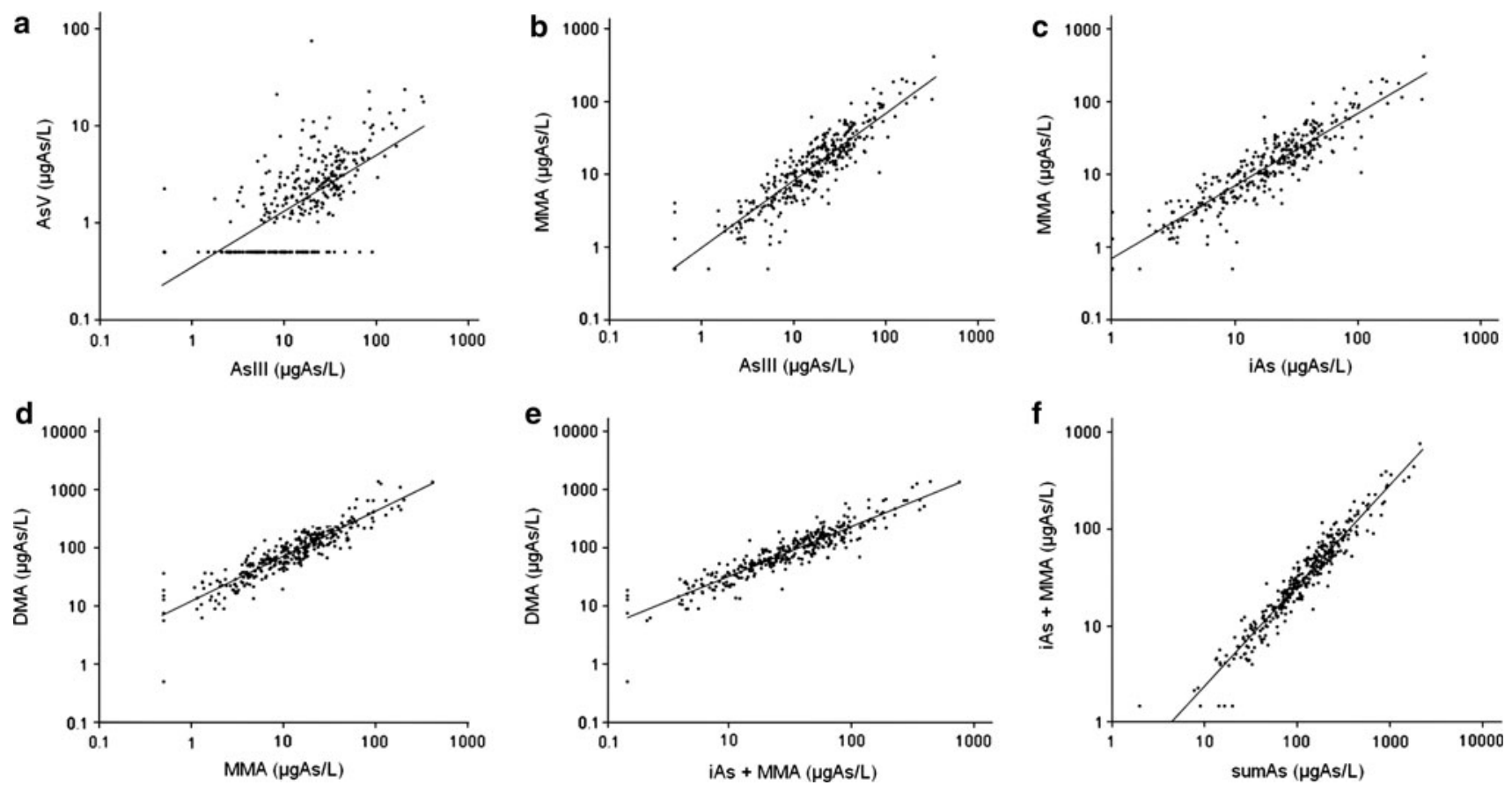

Fig. 2 Relationship between each arsenic species present in urine. a Relationship between AsIII $(x)$ and AsV (y), log $y=0.578$ $\log x-0.456(r=0.654, p<0.0001)$. b Relationship between AsIII $(x)$ and MMA $(y), \log y=0.923 \log x-0.002 \quad(r=0.897$, $p<0.0001)$. c Relationship between iAs $(x)$ and MMA $(y)$, $\log y=0.994 \log x-0.151(r=0.902, p<0.0001)$. d Relationship

relationship between $\mathrm{AsV}$ and other species (Fig. 2; Table 3). Clear correlations were obtained because the arsenic source of the subjects was considered to be iAs originating primarily from groundwater. These results were between MMA $(x)$ and DMA $(y), \log y=0.772 \log x+1.083$ $(r=0.902, \quad p<0.0001)$. e Relationship between iAs + MMA $(x)$ and DMA $(y), \log y=0.858 \log x+0.647 \quad(r=0.921$, $p<0.0001)$. f Relationship between sumAs $(x)$ and iAs + MMA (y), $\log y=1.038 \log x-0.658(r=0.962, p<0.0001)$

confirmed by the following observations: no arsenic metabolites originating in seafood, including AsBe, TMAO, and AsCho, were detected using HPLC-ICP-MS analysis in any urine samples; there was good agreement 
Table 3 Pearson's correlation coefficient between urinary arsenic species

\begin{tabular}{|c|c|c|c|c|c|c|c|}
\hline & $\log ($ AsIII $)$ & $\log (\mathrm{AsV})$ & $\log (\mathrm{MMA})$ & $\log (\mathrm{DMA})$ & $\log \left(\mathrm{iAs} s^{\mathrm{a}}\right)$ & $\log (\mathrm{iAs}+\mathrm{MMA})$ & $\log \left(\operatorname{sumAs}^{\mathrm{b}}\right)$ \\
\hline \multicolumn{8}{|c|}{$\log ($ AsIII $)$} \\
\hline$r$ & 1.000 & 0.654 & 0.897 & 0.893 & 0.988 & 0.972 & 0.932 \\
\hline$p$ & & $<0.001$ & $<0.001$ & $<0.001$ & $<0.001$ & $<0.001$ & $<0.001$ \\
\hline \multicolumn{8}{|c|}{$\log (\mathrm{AsV})$} \\
\hline$r$ & 0.654 & 1.000 & 0.652 & 0.618 & 0.737 & 0.722 & 0.664 \\
\hline$p$ & $<0.001$ & & $<0.001$ & $<0.001$ & $<0.001$ & $<0.001$ & $<0.001$ \\
\hline \multicolumn{8}{|c|}{$\log$ (MMA) } \\
\hline$r$ & 0.897 & 0.652 & 1.000 & 0.902 & 0.902 & 0.964 & 0.935 \\
\hline$p$ & $<0.001$ & $<0.001$ & & $<0.001$ & $<0.001$ & $<0.001$ & $<0.001$ \\
\hline \multicolumn{8}{|c|}{$\log (\mathrm{DMA})$} \\
\hline$r$ & 0.893 & 0.618 & 0.902 & 1.000 & 0.897 & 0.921 & 0.992 \\
\hline$p$ & $<0.001$ & $<0.001$ & $<0.001$ & & $<0.001$ & $<0.001$ & $<0.001$ \\
\hline \multicolumn{8}{|c|}{$\log$ (iAs) } \\
\hline$r$ & 0.988 & 0.737 & 0.902 & 0.897 & 1.000 & 0.982 & 0.940 \\
\hline$p$ & $<0.001$ & $<0.001$ & $<0.001$ & $<0.001$ & & $<0.001$ & $<0.001$ \\
\hline \multicolumn{8}{|c|}{$\log (\mathrm{iAs}+\mathrm{MMA})$} \\
\hline$r$ & 0.972 & 0.722 & 0.964 & 0.921 & 0.982 & 1.000 & 0.962 \\
\hline$p$ & $<0.001$ & $<0.001$ & $<0.001$ & $<0.001$ & $<0.001$ & & $<0.001$ \\
\hline \multicolumn{8}{|c|}{$\log (\operatorname{sum} A s)$} \\
\hline$r$ & 0.932 & 0.664 & 0.935 & 0.992 & 0.940 & 0.962 & 1.000 \\
\hline$p$ & $<0.001$ & $<0.001$ & $<0.001$ & $<0.001$ & $<0.001$ & $<0.001$ & \\
\hline
\end{tabular}

${ }^{a}$ Values are sum of AsIII and AsV

b Values are concentrations of sum of arsenic compounds detected in speciation analysis

between tAs and sumAs; urinary sumAs concentration in these subjects was significantly correlated with iAs concentration of drinking water (Table 4); the subjects did not eat seafood according to the questionnaire; and there were no seafood products available in local markets. Buchet et al. [21] report that iAs biotransformation follows firstorder rate constants and that urinary metabolites have halflives ranging from 39 to $59 \mathrm{~h}$. Despite the relatively short half-lives of iAs metabolites, chronic and constant exposure to iAs exhibits steady states of urinary excretion and significant linear relationships between urinary arsenic species. In particular, the very weak correlation between AsIII and AsV was due to the presence of many samples with very low AsV including 106 out of 330 samples that were lower than the detection limit. Since oxidation and reduction always occur in AsIII and AsV [22], and AsIII can oxidize to AsV during sample transport, storage, and preparation [23], iAs is represented by the sum of AsIII and AsV.

Although many studies report arsenic metabolites in the urine of various populations exposed to iAs-contaminated water using HG-AAS analysis [24], only 3 performed urinary arsenic speciation analysis using HPLC-ICP-MS $[14,15,25]$. Furthermore, the number of subjects in our study was larger than those of these 3 studies. Table 6 summarizes the urine of various populations exposed to iAs-contaminated water using HPLC for separation. Five reports describe urinary arsenic speciation analysis using HPLC-HG-AAS [26-30] as shown in Table 6. The proportions of urinary iAs, MMA, and DMA were 11.4$34.0 \%, 7.5-26.9 \%$, and $47.7-78.8 \%$, respectively. The results of this study are similar to those obtained in a population with $144.7 \mu \mathrm{gAs} / \mathrm{L}$ tAs in West Bengal, India. The proportions are similar to those among various Asian peoples but different from those of Mexicans. Methylation capacity is suggested to differ among ethnicities [24]. The observed difference between Asians and Mexicans is also suggested to be the result of an ethnic difference in methylation capacity.

The correlation coefficient between urinary iAs + MMA concentration and arsenic levels in drinking water is slightly stronger than that between other urinary arsenic species concentrations and arsenic levels in drinking water (Table 4). Total urinary arsenic is commonly used as a biomarker of exposure and is positively correlated with iAs concentration in drinking water in chronically exposed populations [31, 32]. However, in people that eat seafood, significant amounts of tAs are excreted in the urine, including DMA [17, 33, 34]. From the results of the speciation analysis of arsenic in the urine of 172 Japanese 


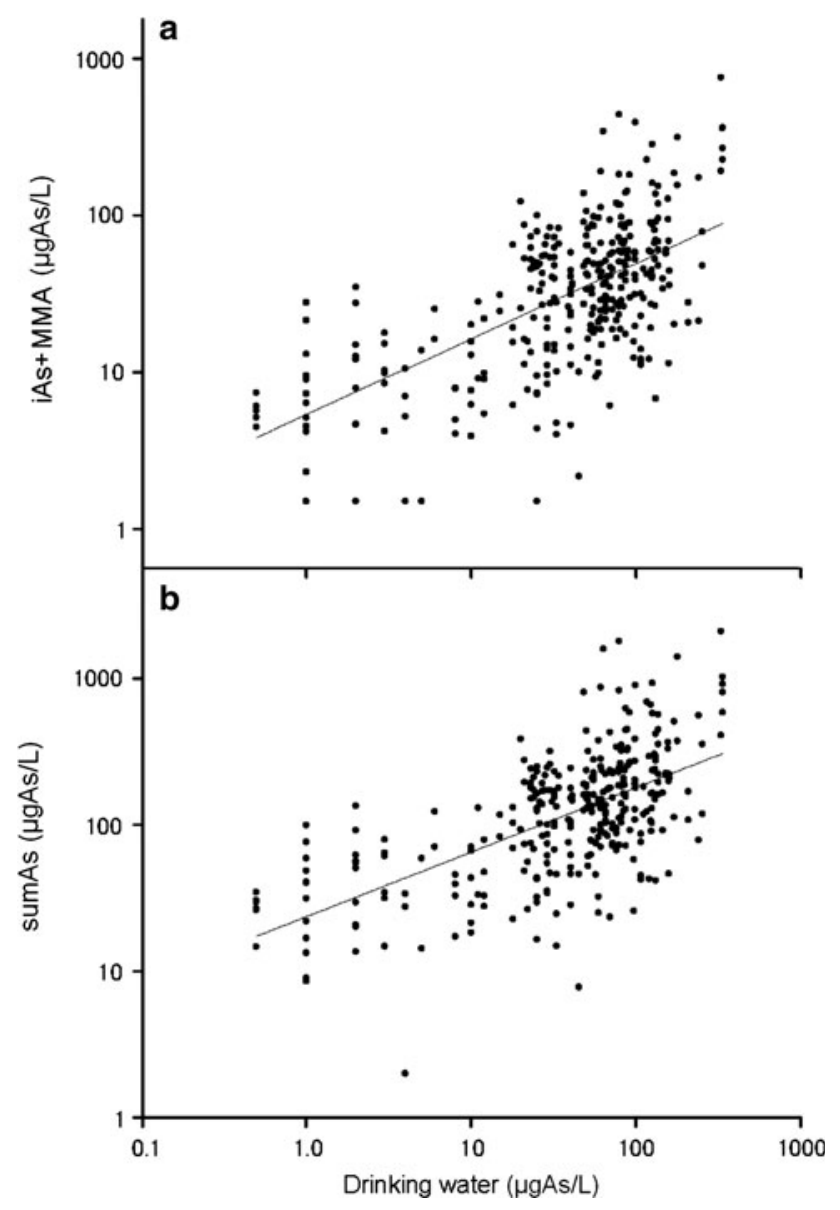

Fig. 3 Scatter plots of the relationships between inorganic arsenic concentrations in drinking water $(x)$ and urinary concentrations $(y)$. a $y=\mathrm{iAs}+\mathrm{MMA}, \mathbf{b} y=\operatorname{sumAs}$

Table 4 Equations of regression between logarithm of iAs in drinking water $(\log x)$ and logarithm of urinary As species $(\log y)$

\begin{tabular}{llll}
\hline Urinary species & Equations & $r$ & $p$ value \\
\hline AsIII & $\log y=0.470 \log x+0.442$ & 0.574 & $<0.0001$ \\
AsV & $\log y=0.358 \log x-0.335$ & 0.495 & $<0.0001$ \\
MMA & $\log y=0.497 \log x+0.308$ & 0.590 & $<0.0001$ \\
DMA & $\log y=0.420 \log x+1.264$ & 0.582 & $<0.0001$ \\
iAs $^{\text {a }}$ & $\log y=0.456 \log x+0.530$ & 0.597 & $<0.0001$ \\
iAs + MMA $_{\text {sumAs }}$ b & $\log y=0.474 \log x+0.744$ & 0.611 & $<0.0001$ \\
\hline
\end{tabular}

${ }^{a}$ Values are sum of AsIII and AsV

b Values are concentrations of sum of arsenic compounds detected in speciation analysis

subjects without occupational exposure to iAs, the highest arsenic concentration in urine was for AsBe followed by DMA; these 2 species accounted for about 50 and $30 \%$ of tAs, respectively [17, 34]. Among male Italian workers inhaling AsIII, the most excreted species was AsBe, accounting for $34 \%$ of the tAs concentration, despite the presence of non-iAs metabolites [35]. In that report, the coefficient of determination between iAs in the air and species present in urine were highest for the sum of iAs, MMA, and DMA $\left(r^{2}=0.75\right)$ and MMA $\left(r^{2}=0.75\right)$, but lowest for DMA $\left(r^{2}=0.53\right)$ [35]. These results clearly show the effects of seafood ingestion on urinary DMA. However, that group did not examine the relationship between iAs in the air and urinary iAs + MMA concentration; instead, they determined the correlation between iAs in the air and urine, and determined that this factor is nearly the same as that between iAs in the air and urinary MMA. Thus, in addition to urinary sumAs concentration, urinary iAs + MMA concentration is a good indicator of iAs exposure. Recently, consumption of seafood has been increasing worldwide. Therefore, the Deutsche Forschungsgemeinschaft (DFG) recommends that only the inorganic arsenic fraction should be determined as the biological tolerance value for iAs exposure in the future [36].

In Fig. 3, urinary iAs + MMA and sumAs concentrations in urine were estimated to be 35.4 and $132.7 \mu \mathrm{gAs} / \mathrm{L}$, respectively, at $50 \mu \mathrm{gAs} / \mathrm{L}$ of iAs in drinking water. The level is the Bangladeshi standard of iAs in drinking water. Although we did not determine the water intake of the subjects, the average amount of water intake and urinary volume in Bangladeshi adults is reported to be 4 and $2 \mathrm{~L} /$ day, respectively [14]. If a subject drinks $4 \mathrm{~L}$ water containing $50 \mu \mathrm{gAs} / \mathrm{L}$, the urinary sumAs concentration would be $70 \mu \mathrm{gAs} / \mathrm{L}$ based on $2 \mathrm{~L}$ urine and a $70 \%$ excretion rate. However, our results show a nearly 2-fold higher value than this estimation. Since iAs-contaminated groundwater is used extensively to irrigate grains and vegetables, in addition to water, food is also contaminated by iAs in Bangladesh [37-40]. The tAs concentration of Bangladesh rice grains ranges from $<0.04$ to $1.83 \mu \mathrm{g} / \mathrm{g}$, and the content of iAs in rice and vegetables is reported to be 87 and $96 \%$ of tAs, respectively [37, 40]. It is estimated that an adult Bangladeshi man consumes an average of $1500 \mathrm{~g}$ cooked rice per day, which contains approximately $435 \mathrm{~g}$ raw rice and at least $1 \mathrm{~L}$ water [41]. Meharg and Rahman [37] report that, at $0.5 \mu \mathrm{gAs} / \mathrm{g}$ grain, arsenic contributes to $51 \%$ of the dietary arsenic intake for those ingesting $2 \mathrm{~L}$ of $0.1 \mathrm{mgAs} / \mathrm{L}$ drinking water and $0.42 \mathrm{~kg}$ of raw rice. Thus, ingestion of rice is a major source of arsenic exposure in Bangladesh.

For assessing human exposure to arsenic, biomonitoring is a useful tool. Urine is the most frequently used biological medium, and speciating arsenic is important for identifying possible factors that contribute to urinary arsenic levels [42]. Arsenic in hair or fingernail can be a biomarker of long-term arsenic exposure, because inorganic arsenic can bind to sulfhydryl groups in keratin and other proteins in the human body. Limitations of hair or nail monitoring include (1) 
Table 5 Effects of BMI, urinary creatinine concentration, and age on proportion of urinary arsenic species and methylation indices among 330 subjects
PMI primary methylation index calculated from urinary MMA/ iAs, SMI secondary methylation index calculated from urinary DMA/MMA

${ }^{\text {a }}$ Values are sum of AsIII and AsV

\begin{tabular}{|c|c|c|c|c|c|}
\hline \multirow[t]{2}{*}{ Item } & \multicolumn{5}{|c|}{ Pearson's correlation coefficient $(r)$ and probability value $(p)$} \\
\hline & $\mathrm{iAs}^{\mathrm{a}}(\%)$ & MMA (\%) & DMA $(\%)$ & PMI & SMI \\
\hline \multicolumn{6}{|c|}{ Total (330) } \\
\hline \multicolumn{6}{|c|}{$\log$ (drinking water) } \\
\hline$r$ & 0.070 & 0.210 & -0.159 & 0.118 & -0.171 \\
\hline$p$ & 0.203 & 0.000 & 0.004 & 0.033 & 0.002 \\
\hline \multicolumn{6}{|c|}{ BMI } \\
\hline$r$ & 0.087 & -0.142 & 0.004 & -0.162 & 0.044 \\
\hline$p$ & 0.117 & 0.010 & 0.942 & 0.003 & 0.424 \\
\hline \multicolumn{6}{|c|}{ Creatinine } \\
\hline$r$ & -0.112 & -0.002 & 0.084 & 0.037 & -0.004 \\
\hline$p$ & 0.043 & 0.971 & 0.126 & 0.499 & 0.948 \\
\hline \multicolumn{6}{|c|}{ Age } \\
\hline$r$ & -0.233 & 0.162 & 0.093 & 0.338 & -0.059 \\
\hline$p$ & 0.000 & 0.003 & 0.093 & 0.000 & 0.284 \\
\hline \multicolumn{6}{|c|}{ Male (165) } \\
\hline \multicolumn{6}{|c|}{$\log ($ drinking water $)$} \\
\hline$r$ & 0.115 & 0.315 & -0.249 & 0.196 & -0.192 \\
\hline$p$ & 0.142 & 0.000 & 0.001 & 0.011 & 0.013 \\
\hline \multicolumn{6}{|c|}{ BMI } \\
\hline$r$ & 0.010 & -0.075 & 0.028 & -0.110 & 0.013 \\
\hline$p$ & 0.896 & 0.338 & 0.718 & 0.158 & 0.873 \\
\hline \multicolumn{6}{|c|}{ Creatinine } \\
\hline$r$ & -0.055 & -0.042 & 0.053 & -0.016 & 0.008 \\
\hline$p$ & 0.487 & 0.590 & 0.497 & 0.836 & 0.915 \\
\hline \multicolumn{6}{|c|}{ Age } \\
\hline$r$ & -0.147 & 0.061 & 0.055 & 0.235 & -0.066 \\
\hline$p$ & 0.059 & 0.435 & 0.483 & 0.002 & 0.399 \\
\hline \multicolumn{6}{|c|}{ Female (165) } \\
\hline \multicolumn{6}{|c|}{$\log ($ drinking water $)$} \\
\hline$r$ & 0.043 & 0.098 & -0.080 & 0.038 & -0.148 \\
\hline$p$ & 0.582 & 0.211 & 0.305 & 0.627 & 0.058 \\
\hline \multicolumn{6}{|c|}{ BMI } \\
\hline$r$ & 0.095 & -0.164 & -0.009 & -0.159 & 0.056 \\
\hline$p$ & 0.225 & 0.036 & 0.913 & 0.042 & 0.471 \\
\hline \multicolumn{6}{|c|}{ Creatinine } \\
\hline$r$ & -0.101 & -0.051 & 0.106 & -0.009 & 0.018 \\
\hline$p$ & 0.198 & 0.512 & 0.176 & 0.906 & 0.819 \\
\hline \multicolumn{6}{|c|}{ Age } \\
\hline$r$ & -0.210 & 0.104 & 0.127 & 0.294 & 0.030 \\
\hline$p$ & 0.007 & 0.185 & 0.105 & 0.000 & 0.698 \\
\hline
\end{tabular}

potential for external contamination, (2) absence of standardized analytical methods, and (3) absence of a welldefined reference range [42]. Therefore, to assess human exposure to iAs, it is essential to determine the arsenic speciation in urine.

In this study, iAs concentration in drinking water ranged from 0.5 to $332 \mu \mathrm{g} / \mathrm{L}$, and approximately $86 \%$ of residents drank water with iAs concentration exceeding the World
Health Organization (WHO) reference value of $10 \mu \mathrm{g} / \mathrm{L}$. Nearly $50 \%$ of the population drank water with iAs concentration exceeding $50 \mu \mathrm{g} / \mathrm{L}$ of the Bangladeshi standard (Table 1). This distribution of iAs concentration in drinking water is correlated with that of a large population study in Bangladesh (HEALS); the HEALS study aimed to clarify the health effects of arsenic exposure at low to moderate levels (100-300 $\mu \mathrm{g} / \mathrm{L})$ [43]. Arsenic methylation 


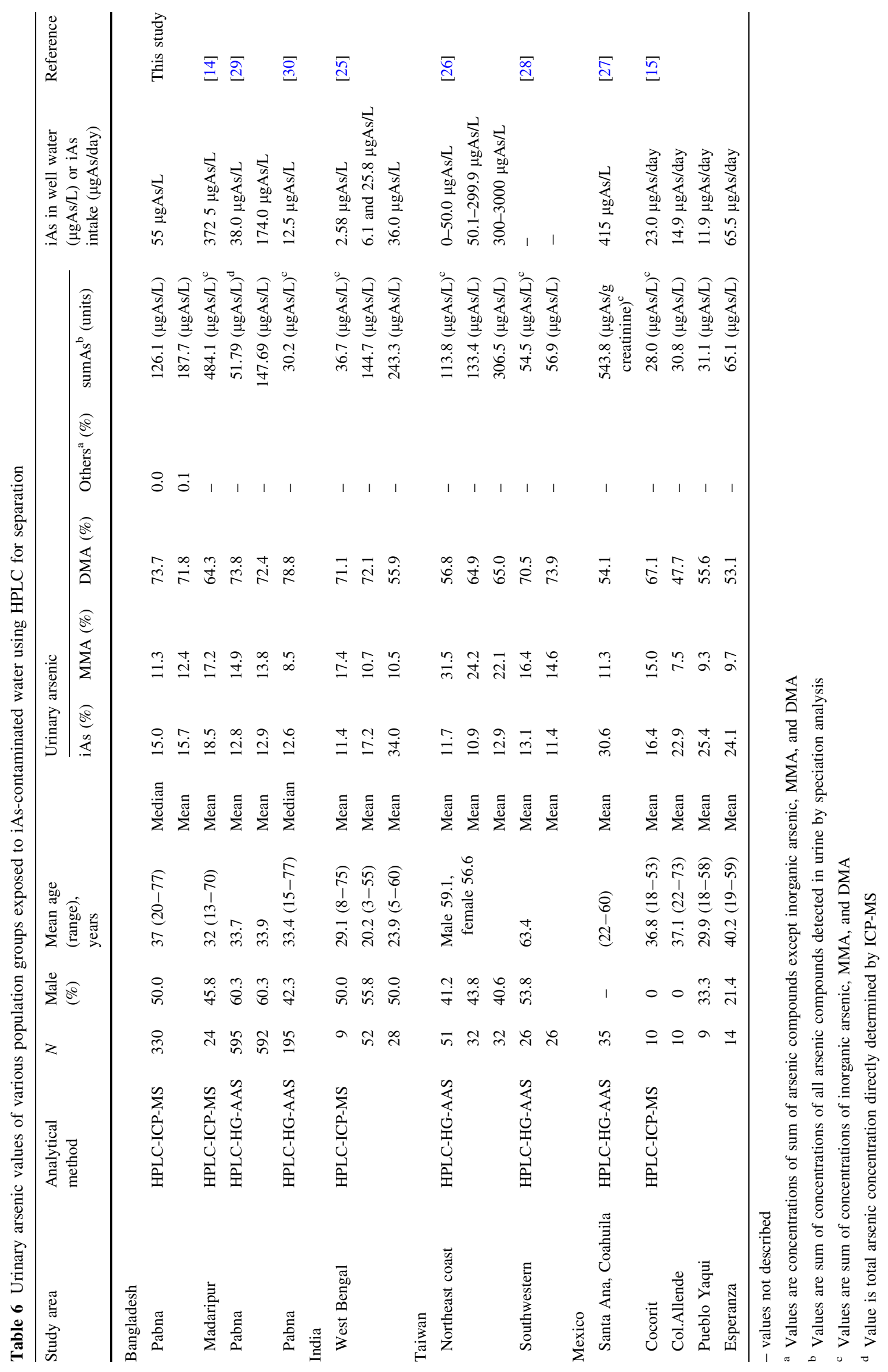


capacity is reported to be a risk factor for arsenic-related toxicity because \%MMA is most strongly associated with an increased risk of arsenic-induced skin lesions [23, 32]. In our study, iAs in drinking water was significantly positively correlated with the proportions of MMA and PMI, but significantly negatively correlated with the proportions of DMA and SMI in males. However, these correlations were not significant in females (Table 5). These results are concordant with those of previous reports in which PMI was elevated and SMI was depressed in males with high tAs; furthermore, these are related to skin lesions [16, 23, 27, 28, 44]. A significant positive correlation between age and PMI in both males and females in our study is consistent with the results of a report in which older people were more likely to be affected by arsenic exposure [45]. It is reported that urinary creatinine is a predictor of arsenic methylation and higher urinary creatinine concentrations are associated with a reduced risk of skin lesions [23, 46, 47]. Although our subjects exhibited a very wide range of urinary creatinine concentrations, neither PMI nor SMI were associated with urinary creatinine concentrations. Urinary creatinine concentrations were strongly correlated with muscle mass and were affected by red meat intake [20]. There was no correlation between urinary creatinine and BMI among our 330 subjects. Tseng et al. [44] report that BMI is positively correlated with DMA and negatively correlated with MMA. Our results show that BMI is significantly negatively correlated with both MMA (\%) and PMI. This result supports the hypothesis that lower BMI is related to the risk of developing skin lesions [45].

The HEALS study included more than 20000 men and women. Chen et al. [32] report that there is little intrasubject variability regarding urinary arsenic metabolite profiles, thus justifying the use of single measurements in epidemiologic studies. In addition, Kile et al. [30] report that, although urinary arsenic ratios are poorly reproducible, urinary arsenic concentrations are fairly reproducible according to the results of longitudinal studies conducted in Bangladesh. Thus, our results apply to residents drinking water with low to moderate levels of arsenic contamination in Bangladesh. Moreover, because seafood ingestion does not affect urinary iAs + MMA concentrations, urinary iAs + MMA concentration is the best indicator of iAs exposure not only in Bangladesh, but for all populations exposed to iAs.

\section{Conclusions}

In 330 subjects continuously exposed to iAs who did not ingest seafood, strong correlations and linear regressions among urinary AsIII, AsV, MMA, and DMA were observed over a wide range of concentrations. All urinary species were well correlated with iAs in drinking water, and the most significant linear relationship was obtained between iAs in drinking water and urinary iAs + MMA concentration. Thus, urinary iAs + MMA concentration is a useful biomarker for assessing chronic iAs exposure.

Acknowledgments This work was supported in part by a Grant-inAid for Scientific Research (nos. 20390173, 20406029, and 21790558) from the Ministry of Education, Culture, Sports, Science, and Technology of Japan.

Conflict of interest The authors have no conflicts of interest to declare.

\section{References}

1. Dhar RKr, Biswas BKr, Samanta G, BKr Mandal, Chakraborti D, Roy S, et al. Groundwater arsenic calamity in Bangladesh. Curr Sci. 1997;73:48-59.

2. Smith AH, Lingas EO, Rahman M. Contamination of drinkingwater by arsenic in Bangladesh: a public health emergency. Bull World Health Organ. 2000;78:1093-103.

3. Habib A, Hayashi T, Sato KK, Hata A, Ikebe M, Rahman F, et al. Effectiveness of arsenic mitigation program in Bangladeshrelationship between arsenic concentrations in well water and urine. Osaka City Med J. 2007;53:97-103.

4. International Agency for Research on Cancer (IARC). Some drinking water disinfectants and contaminants, including arsenic. IARC Monogr Eval Carcinog Risks Hum. 2004;84:36-267.

5. Vahter M. Mechanisms of arsenic biotransformation. Toxicology. 2002;181-182:211-7.

6. Wei M, Wanibuchi H, Morimura K, Iwai S, Yoshida K, Endo G, et al. Carcinogenicity of dimethylarsinic acid in male F344 rats and genetic alterations in induced urinary bladder tumors. Carcinogenesis. 2002;23:1387-97.

7. Kligerman $\mathrm{AD}$, Doerr CL, Tennant AH, Harrington-Brock K, Allen JW, Winkfield E, et al. Methylated trivalent arsenicals as candidate ultimate genotoxic forms of arsenic: induction of chromosomal mutations but not gene mutations. Environ Mol Mutagen. 2003;42:192-205.

8. Yamanaka K, Kato K, Mizoi M, An Y, Takabayashi F, Nakano $\mathrm{M}$, et al. The role of active arsenic species produced by metabolic reduction of dimethylarsinic acid in genotoxicity and tumorigenesis. Toxicol Appl Pharmacol. 2004;198:385-93.

9. Mizoi M, Takabayashi F, Nakano M, An Y, Sagesaka Y, Kato K, et al. The role of trivalent dimethylated arsenic in dimethylarsinic acid-promoted skin and lung tumorigenesis in mice: tumor-promoting action through the induction of oxidative stress. Toxicol Lett. 2005;158:87-94.

10. International Agency for Research on Cancer (IARC). Agents classified by the IARC monographs, vol 1-100. Lyon: IARC. http://monographs.iarc.fr/ENG/Classification/Classifications AlphaOrder.pdf (2010). Accessed 10 Dec 2010.

11. Hopenhayn-Rich C, Biggs ML, Smith AH, Kalman DA, Moore LE. Methylation study of a population environmentally exposed to arsenic in drinking water. Environ Health Perspect. 1996;104:620-8.

12. Chen YC, Su HJ, Guo YL, Hsueh YM, Smith TJ, Ryan LM, et al. Arsenic methylation and bladder cancer risk in Taiwan. Cancer Causes Control. 2003;14:303-10.

13. Tseng $\mathrm{CH}$. Arsenic methylation, urinary arsenic metabolites and human diseases: current perspective. J Environ Sci Health C Environ Carcinog Ecotoxicol Rev. 2007;25:1-22. 
14. Chowdhury UK, Rahman MM, Sengupta MK, Lodh D, Chanda $\mathrm{CR}$, Roy S, et al. Pattern of excretion of arsenic compounds [arsenite, arsenate, MMA(V), DMA(V)] in urine of children compared to adults from an arsenic exposed area in Bangladesh. J Environ Sci Health A Tox Hazard Subst Environ Eng. 2003;38:87-113.

15. Meza MM, Kopplin MJ, Burgess JL, Gandolfi AJ. Arsenic drinking water exposure and urinary excretion among adults in the Yaqui Valley, Sonora, Mexico. Environ Res. 2004;96:119-26.

16. Parvez F, Chen Y, Brandt-Rauf PW, Bernard A, Dumont X, Slavkovich V, et al. Nonmalignant respiratory effects of chronic arsenic exposure from drinking water among never-smokers in Bangladesh. Environ Health Perspect. 2008;116:190-5.

17. Hata A, Endo Y, Nakajima Y, Ikebe M, Ogawa M, Fujitani N, et al. HPLC-ICP-MS speciation analysis of arsenic in urine of Japanese subjects without occupational exposure. J Occup Health. 2007;49:217-23.

18. Nakajima Y, Endo Y, Inoue Y, Yamanaka K, Kato K, Wanibuchi $\mathrm{H}$, et al. Ingestion of Hijiki seaweed and risk of arsenic poisoning. Appl Organometal Chem. 2006;20:557-64.

19. German Federal Environment Agency. Standardisation of substance concentrations in urine. Creatinine. Bundesgesundheitsbl Gesundheitsforsch Gesundheitsschutz. 2005;48:616-8.

20. Barr DB, Wilder LC, Caudill SP, Gonzalez AJ, Needham LL, Pirkle JL. Urinary creatinine concentrations in the U.S. population: implications for urinary biologic monitoring measurements. Environ Health Perspect. 2005;113:192-200.

21. Buchet JP, Lauwerys R, Roels H. Urinary excretion of inorganic arsenic and its metabolites after repeated ingestion of sodium metaarsenite by volunteers. Int Arch Occup Environ Health. 1981;48:111-8.

22. Agency for Toxic Substances and Disease Registry (ATSDR). Toxicological profile for arsenic. Georgia: ATSRD, U.S. Department of Health and Human Services; 2007.

23. Ahsan H, Chen Y, Kibriya MG, Slavkovich V, Parvez F, Jasmine $\mathrm{F}$, et al. Arsenic metabolism, genetic susceptibility, and risk of premalignant skin lesions in Bangladesh. Cancer Epidemiol Biomarkers Prev. 2007;16:1270-8.

24. Tseng $\mathrm{CH}$. A review on environmental factors regulating arsenic methylation in humans. Toxicol Appl Pharmacol. 2009;235:338-50.

25. Tokunaga $H$, Roychowdhury $T$, Uchino $T$, Ando $M$. Urinary arsenic species in arsenic-affected area of West Bengal, India (Part II). J Health Sci. 2003;46:464-74.

26. Chiou H-Y, Hsueh Y-M, Hsieh L-L, Hsu L-I, Hsu Y-H, Hsieh F-I, et al. Arsenic methylation capacity, body retention, and null genotypes of glutathione S-transferase M1 and T1 among current arsenicexposed residents in Taiwan. Mutat Res. 1997;386:197-207.

27. Del Razo LM, Garcia-Vargas GG, Vargas H, Albores A, Gonsebatt ME, Montero R, et al. Altered profile of urinary arsenic metabolites in adults with chronic arsenicism. A pilot study. Arch Toxicol. 1997;71:211-7.

28. Yu RC, Hsu KH, Chen CJ, Froines JR. Arsenic methylation capacity and skin cancer. Cancer Epidemiol Biomarkers Prev. 2000;9:1259-62.

29. McCarty KM, Chen YC, Quamruzzaman Q, Rahman M, Mahiuddin G, Hsueh YM, et al. Arsenic methylation, GSTT1, GSTM1, GSTP1 polymorphisms, and skin lesions. Environ Health Perspect. 2007;115:341-5.

30. Kile ML, Hoffman E, Hsueh YM, Afroz S, Quamruzzaman Q, Rahman M, et al. Variability in biomarkers of arsenic exposure and metabolism in adults over time. Environ Health Perspect. 2009;117:455-60.

31. Watanabe $\mathrm{C}$, Inaoka $\mathrm{T}$, Kadono $\mathrm{T}$, Nagano M, Nakamura $\mathrm{S}$, Ushijima $\mathrm{K}$, et al. Males in rural Bangladeshi communities are more susceptible to chronic arsenic poisoning than females: analyses based on urinary arsenic. Environ Health Perspect. 2001;109:1265-70.

32. Chen Y, Parvez F, Gamble M, Islam T, Ahmed A, Argos M, et al. Arsenic exposure at low-to-moderate levels and skin lesions, arsenic metabolism, neurological functions, and biomarkers for respiratory and cardiovascular diseases: review of recent findings from the Health Effects of Arsenic Longitudinal Study (HEALS) in Bangladesh. Toxicol Appl Pharmacol. 2009;239:184-92.

33. Morton J, Mason H. Speciation of arsenic compounds in urine from occupationally unexposed and exposed persons in the U.K. using a routine LC-ICP-MS method. J Anal Toxicol. 2006;30: 293-301.

34. Suzuki Y, Shimoda Y, Endo Y, Hata A, Yamanaka K, Endo G. Rapid and effective speciation analysis of arsenic compounds in human urine using anion-exchange columns in HPLC-ICP-MS. J Occup Health. 2009;51:380-5.

35. Apostoli P, Bartoli D, Alessio L, Buchet JP. Biological monitoring of occupational exposure to inorganic arsenic. Occup Environ Med. 1999;56:825-32.

36. Deutsche Forschungsgemeinschaft (DFG). Arsenic and inorganic arsenic compounds. Essential BAT value documentations. Weinheim: Wiley; 2006.

37. Meharg AA, Rahman MM. Arsenic contamination of Bangladesh paddy field soils: implications for rice contribution to arsenic consumption. Environ Sci Technol. 2003;37:229-34.

38. Das HK, Mitra AK, Sengupta PK, Hossain A, Islam F, Rabbani $\mathrm{GH}$. Arsenic concentrations in rice, vegetables, and fish in Bangladesh: a preliminary study. Environ Int. 2004;30:383-7.

39. Williams PN, Price AH, Raab A, Hossain SA, Feldmann J, Meharg AA. Variation in arsenic speciation and concentration in paddy rice related to dietary exposure. Environ Sci Technol. 2005;39:5531-40.

40. Smith NM, Lee R, Heitkemper DT, DeNicola Cafferky K, Haque A, Henderson AK. Inorganic arsenic in cooked rice and vegetables from Bangladeshi households. Sci Total Environ. 2006; 370:294-301.

41. Bae M, Watanabe C, Inaoka T, Sekiyama M, Sudo N, Bokul MH, et al. Arsenic in cooked rice in Bangladesh. Lancet. 2002; 360:1839-40.

42. Orloff K, Mistry K, Metcalf S. Biomonitoring for environmental exposures to arsenic. J Toxicol Environ Health B Crit Rev. 2009;12:509-24.

43. Parvez F, Chen Y, Argos M, Hussain AZ, Momotaj H, Dhar R, et al. Prevalence of arsenic exposure from drinking water and awareness of its health risks in a Bangladeshi population: results from a large population-based study. Environ Health Perspect. 2006;114:355-9.

44. Tseng CH, Huang YK, Huang YL, Chung CJ, Yang MH, Chen $\mathrm{CJ}$, et al. Arsenic exposure, urinary arsenic speciation, and peripheral vascular disease in blackfoot disease-hyperendemic villages in Taiwan. Toxicol Appl Pharmacol. 2005;206:299-308.

45. Ahsan H, Chen Y, Parvez F, Zablotska L, Argos M, Hussain I, et al. Arsenic exposure from drinking water and risk of premalignant skin lesions in Bangladesh: baseline results from the Health Effects of Arsenic Longitudinal Study. Am J Epidemiol. 2006; 163:1138-48.

46. Gamble MV, Liu X, Ahsan H, Pilsner R, Ilievski V, Slavkovich $\mathrm{V}$, et al. Folate, homocysteine, and arsenic metabolism in arsenic-exposed individuals in Bangladesh. Environ Health Perspect. 2005;113:1683-8.

47. Pilsner JR, Liu X, Ahsan H, Ilievski V, Slavkovich V, Levy D, et al. Folate deficiency, hyperhomocysteinemia, low urinary creatinine, and hypomethylation of leukocyte DNA are risk factors for arsenic-induced skin lesions. Environ Health Perspect. 2009; 117:254-60. 